\title{
Effect of gestational protein restriction on left ventricle hypertrophy and heart angiotensin II signaling pathway in adult offspring rats
}

\author{
Renan Brisolla da Silva ${ }^{1}$, Flávia Fernandes Mesquita ${ }^{2}$, Marília Andreo ${ }^{1}$, \\ Heloisa Balan Assalin ${ }^{1,2}$, José Antônio Rocha Gontijo ${ }^{2}$, Patrícia Aline Boer ${ }^{1,2 \#}$ \\ ${ }^{1}$ Fetal Programming Laboratory, Department of Morphology, Botucatu Bioscience Institute, UNESP-São Paulo State University, \\ Botucatu, Brazil \\ ${ }^{2}$ Hydro-Saline Metabolism Laboratory, Internal Medicine Department, Faculty of Medical Sciences, State University of Campinas, \\ Campinas, Brazil; " Corresponding Author: alineboer@yahoo.com.br
}

Received 6 March 2012; revised 5 April 2012; accepted 21 April 2012

Copyright (C) 2013 Renan Brisolla da Silva et al. This is an open access article distributed under the Creative Commons Attribution License, which permits unrestricted use, distribution, and reproduction in any medium, provided the original work is properly cited.

\section{ABSTRACT}

Maternal protein restriction may be a risk factor for cardiovascular disorders in adulthood. The RAS (renin-angiotensin-system) plays a pivotal role in cardiac remodeling. Components of the RAS, including angiotensin II (AngII) and its receptors type 1 (AT1R) and 2 (AT2R) are expressed in the heart. This study investigates whether gestational protein restriction alters the expression and localization of AT1R and AT2R and RAS signaling pathway proteins in parallel with left ventricle hypertrophy and systemic hypertension in male offspring. Dams were kept on normal (NP, $17 \%$ protein) or low (LP, $6 \%$ protein) protein diet during pregnancy. Systolic blood pressure (SBP) of male offspring was measured from the $8^{\text {th }}$ to $16^{\text {th }}$ week and left ventricles of 16-wk-old rats were processed for histology, morphometric, immunoblotting and immunohistochemistry. LP offspring showed a significant reduction in birth body weight and SBP increased significantly from the $8^{\text {th }}$ week. Left ventricle mass and cardiomyocytes area were also significantly higher in LP animals. Widespread perivascular fibrosis was not detected in the heart tissue. Analysis by immunoblotting and immunohistochemistry demonstrated a significant enhance in cardiomyocyte expression of AT1R and ERK1 in LP offspring. Expression of PI3K in LP was significantly reduced in cardiomyocytes and in the intramural coronary wall, while AT2R expression was unchanged in the

\footnotetext{
${ }^{*}$ We affirm that there is no conflict of interest.
}

NP group. We also found reduced LP expression of JAK2 and STAT3. In conclusion, our data also suggest that changes in the RAS may play a role in the ventricular growth through upregulation of the AT1-mediated ERK1/2 response, despite unchanged $A T 2 R$ expression.

Keywords: Low Birth Weight; Arterial Hypertension; Fetal Programming; Protein Restriction; Angiotensin II; Left Ventricle Hypertrophy; Cardiovascular Disease

\section{INTRODUCTION}

Nutritional alterations and fetal endogen patterns lead to the development of physiological and metabolic changes, predisposing the individual to metabolic, endocrine and cardiovascular diseases in adult life [1]. Alterations in nutrition and endocrine status during the embryonic, fetal and neonatal periods can trigger developmental predictive adaptive responses, causing permanent structural, physiological and metabolic changes, thereby predisposing individuals to cardiovascular, metabolic and endocrine diseases in adult life [2]. The renin-angiotensin system (RAS) plays an important role in primary and secondary forms of hypertension. Components of the RAS, such angiotensin II (AngII) are locally produced in the cardiac tissues [3], and are primary candidates for the factors promoting remodeling, mainly cardiac myocyte hypertrophy and increased extracellular fibrosis, thereby deteriorating cardiac functions [4]. Various experimental animal models have been developed to investigate the associations between fetal undernutrition and cardiovascular disease later in life $[5,6]$, and a possible commit- 
ment of a systemic RAS in the developmental origins of hypertension has been reported [7]. Taking in account the data above, the aim of this study was to investigate whether maternal protein restriction alters, in adult rats, the expression and localization of myocardial AT1R (type 1 angiotensin II receptor) and AT2R (type 2 angiotensin receptor) and RAS signaling pathway proteins (ERK1/2 [extracellular signal-related kinase 1 and 2], PI3K [phosphatidylinositol 3-kinase], JAK2 [Janus kinase 2] and STAT3 [signal transducers and activated transcription 3]. Also, determine whether these possible molecular changes occur in parallel with development of left ventricle hypertrophy and collagen distribution and, systemic hypertension in 16-wk-old male offspring.

\section{METHODS}

\subsection{Animals}

The experiments were conducted on age-matched, female offspring of sibling-mated Wistar Hannover rats. The general guidelines established by the Brazilian College of Animal Experimentation (COBEA) were followed throughout the investigation. Our local colonies originated from a breeding stock supplied by CEMIB/UNICAMP, Campinas, SP, Brazil. Ten females were mated and were maintained on isocaloric standard rodent laboratory with normal protein content $[\mathrm{NP}, \mathrm{n}=5]$ (17\% protein) or low protein content [LP, $\mathrm{n}=5]$ ( $6 \%$ protein) chow ad libitum intake throughout the entire pregnancy. All groups returned to isocaloric standard chow intake after delivery. For the experiments, we used male pupsfrom randomized dams $[8,9]$.

\subsection{Blood Pressure Measurement}

The systolic blood pressure (SBP) was measured in conscious male offspring at 8 to 16 weeks of age, employing an indirect tail-cuff method using an electrosphygmomanometer combined with a pneumatic pulse transducer/amplifier (IITC Life Science). This indirect approach allowed repeated measurements with a close correlation (correlation coefficient $=0.975)$, compared to direct intra-arterial recording [10,11]. The mean of three consecutive readings represented the blood pressure. All the maleoffspring were used.

\subsection{Tissue Processing, Histology, Morphometry and Immunohistochemical Procedures}

Sixteen-week-old male offspring from the NP $(n=5)$ and LP $(\mathrm{n}=5)$ groups were anesthetized with ketamine (75 $\mathrm{mg} \cdot \mathrm{kg}^{-1}$ body weight, i.p.) and xylasine $\left(10 \mathrm{mg} \cdot \mathrm{kg}^{-1}\right.$ body weight, i.p.). The animals were perfused by the left carotid artery with saline containing heparin (5\%) for 15 min. Then followed by perfusion with $0.1 \mathrm{M}$ phosphate buffer ( $\mathrm{pH} 7.4$ ) containing 4\% (w/v) paraformaldehyde for $25 \mathrm{~min}$. After perfusion, the cardiac left ventricles were removed and representative samples were fixed in $4 \%$ phosphate-buffered formalin during $24 \mathrm{~h}$ for paraffin embedding. Five-micrometer-thick sections were cut from the blocked tissue and stained with hematoxylin-eosin. Cardiomyocytes cross-sectional area was determined for at least 100 myocytes per slide stained with hematoxylin-eosin. The measurements were performed using a Leica microscope ( $\times 40$ magnification lens) attached to a video camera and connected to a personal computer equipped with image analyzer software (Image Pro Express 6.0, Media Cybernetics, Inc.). Cardiomyocyte area was measured with a digitizing pad, and the selected cells were transversely cut with the nucleus clearly identified in the center of the myocyte. Other sections were stained with Sirius Red to evaluate interstitial and perivascular fibrosis. For immunohistochemical analysis we use anti-AT1R, AT2R, ERK1/2, PI3K, JAK2 and STAT3 antibodies (Santa Cruz Biotech, Inc., CA, USA). Antigen retrieval was performed using $0.01 \mathrm{M}$ citrate buffer $(\mathrm{pH}$ $6.0)$ boiling in microwave oven $(1.300 \mathrm{~W})$ twice for 5 min each. Proteins were immunohistochemically detected using the avidin-biotin-peroxidase method. Briefly, deparaffinized 5 - $\mu \mathrm{m}$-thick heart sections on poly-1-lysine coated slides were treated with $3 \% \mathrm{H}_{2} \mathrm{O}_{2}$ in phosphatebuffered saline for $15 \mathrm{~min}$, nonfat milk for $60 \mathrm{~min}$, primary antibodies for $60 \mathrm{~min}$, and avidin-biotin-peroxidase solution (Vector Laboratories Inc., CA, USA, 1:1:50 dilution). Chromogen color was accomplished with 3,3'diaminobenzidine tetrahydrochroride (DAB, Sigma-Aldrich Co., St. Louis MO, USA) as the substrate to demonstrate the sites of peroxidase binding. The slides were counterstained with Harris's hematoxylin.

\subsection{Western Blot Analysis}

Sixteen-week-old male offspring rat from the NP $(\mathrm{n}=$ 5) and LP $(n=5)$ groups had their neck dislocated, and the abdominal cavity was opened for cardiac left ventricle removal. The tissue was minced coarsely and homogenized immediately in 10 volumes of solubilization buffer $(10 \mathrm{ml} / \mathrm{L}$ Triton-X 100, $100 \mathrm{mM}$ Tris [hydroxymethyl]amino-methane (Tris) $\mathrm{pH} 7.4,10 \mathrm{mM}$ sodium pyrophosphate, $100 \mathrm{mM}$ sodium fluoride, $10 \mathrm{mM}$ ethylendiaminetetracetic acid (EDTA), $10 \mathrm{mM}$ sodium vanadate, $2 \mathrm{mM}$ phenylmethylsulfonyl fluoride (PSMF) and 0.1 $\mathrm{mg} / \mathrm{ml}$ aprotinin at $4^{\circ} \mathrm{C}$, using a polytron PTA $20 \mathrm{~S}$ generator (model PT 10/35, Brinkmann Instruments, Westbury, NY, USA) operated at maximum speed for $20 \mathrm{~s}$. The tissue extracts were centrifuged at $11.000 \mathrm{rpm}$ at $4^{\circ} \mathrm{C}$ for $40 \mathrm{~min}$, and the supernatants used as sample. 


\subsection{Antibodies and Chemicals}

Protein quantification was performed using the Bradford method. For quantification, both tissue and total extract samples (250 $\mu \mathrm{g}$ protein) were subjected to SDSPAGE. After electrophoretic separation, proteins were transferred to nitrocellulose membranes and then blotted with specific antibody. The samples were treated with Laemmli buffer containing $100 \mathrm{mM}$ dithiothreitol (DTT), heated in a boiling water bath for $4 \mathrm{~min}$ and subjected to $8 \%$ sodium dodecyl sulfate-polyacrylamide gel electrophoresis (SDS-PAGE) in a Bio-Rad minigel apparatus (Mini-Protean, Bio-Rad). Electrotransfer of proteins from the gel to the nitrocellulose membranes was performed for $90 \mathrm{~min}$ at $120 \mathrm{~V}$ (constant) in a Bio-Rad miniature transfer apparatus (Mini-Protean). The non-specific protein binding to the nitrocellulose was reduced by preincubating the filter for $2 \mathrm{~h}$ at $22^{\circ} \mathrm{C}$ in blocking buffer $(5 \%$ non-fat dry milk, $10 \mathrm{mM}$ Tris, $150 \mathrm{mM} \mathrm{NaCl}$, and $0.02 \%$ Tween 20). The nitrocellulose blots were incubated at $4^{\circ} \mathrm{C}$ overnight with primary antibodies diluted in blocking buffer (3\% non-fat dry milk, $10 \mathrm{mM}$ Tris, $150 \mathrm{mM}$ $\mathrm{NaCl}$, and $0.02 \%$ Tween 20 ). Immunoreactive bands were detected usingthe enhanced chemiluminescence method (RPN 2108 ECL Westernblotting analysis system; Amersham Biosciences) and were detected by autoradiography using preflashed Kodak XAR film (Eastman Kodak, Rochester, NY) with Cronex Lightning Plus intensifying screen (DuPont, Wilmington, DE) for $10 \mathrm{~min}$. Images of the developed radiographs were scanned (Epson Stylus 3500) and band intensities were quantified by optical densitometry (Scion Image Corporation). To ensure equal loading, membranes were stained with reversible Ponceau to discard possible inequalities in protein loading and/or transfer, in western blots [12]. Only homogeneously stained membranes were employed in the study.

\subsection{Statistical Analysis}

All numerical results are expressed as the mean \pm SEM of the indicated number of experiments. Data obtained over time were analyzed using one-way ANOVA. Post-hoc comparisons between selected means were performed with Bonferroni's contrast test when initial ANOVA indicated statistical differences between experimental groups. Comparisons involving only two means within or between groups were carried out using a Student's t test. The results of blots are presented as direct comparisons of bands in autoradiographs and quantified by densitometry using the Scion Image software (ScionCorp). The level of significance was set at $\mathrm{P} \leq 0.05$.

\section{RESULTS}

The birth weight of the LP male pups was significantly reduced when compared to NP male pups $(6.15 \pm 0.16$ g vs. $6.72 \pm 0.41 \mathrm{~g}$ respectively, $\mathrm{P}=0.008)$. Systolic blood pressure (SBP) was significantly higher in LP than in NP rats from 8 to 16 weeks of age (Figure 1). The weight of the left ventricle (NP: $0.1729 \pm 0.001$ vs. LP: $0.1874 \pm 0.001, \mathrm{P}<0.001)$ and the cardiomyocyte area (Figure 2) enhanced significantly in 16-wk-old LP rats, indicative of hypertrophy. Sirius Red techniques did not demonstratea significant interstitial or perivascular fibrosis in the cardiac left ventricle of LP group at 16 weeks of age; conversely, there was a pronounced reduction in collagen content in both the interstitial and intramural coronary tissues (Figure 3).

\section{Western Blot and Immunohistochemical Analysis of RAS Signaling Proteins}

Western blot analysis in male offspring of NP and LP cardiac left ventricle yielded a single band at the expected weight of corresponding proteins. Heart AT2R expression was unchanged when compared to NP group (NP: $12.14 \pm 0.09$ vs. LP: $12.02 \pm 0.72, \mathrm{P}=0.8$, Figure

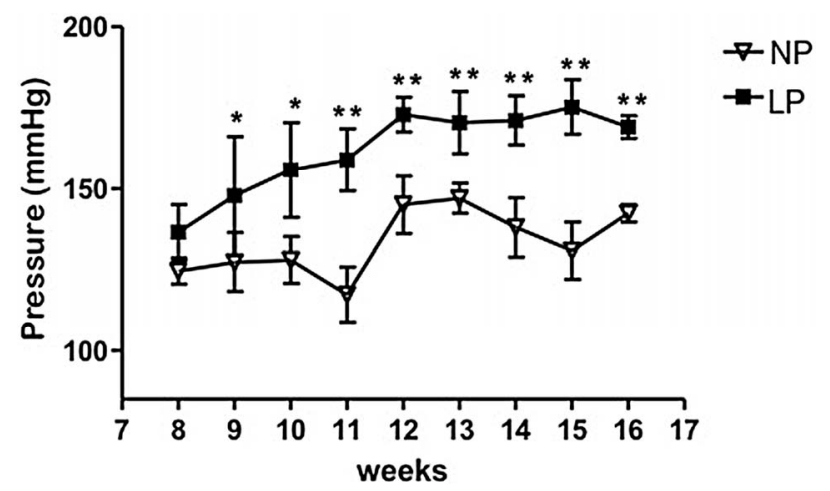

Figure 1. Effects of age on arterial pressure in male offspring of protein-restricted and basal diet mothers during gestation. The data are reported as the means \pm SEM. ${ }^{*} \mathrm{P} \leq 0.05$ and ${ }^{* *} \mathrm{P}=$ 0.0001 vs. control.

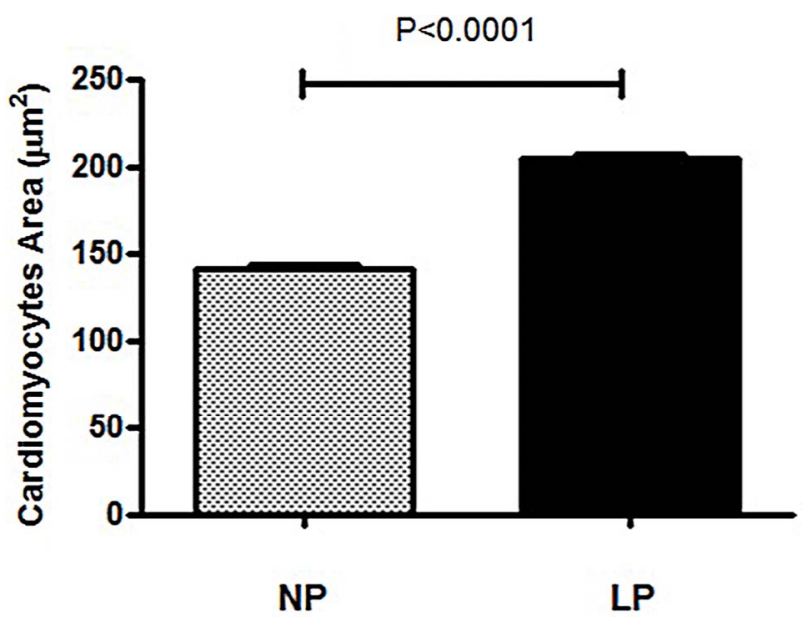

Figure 2. Cardiomyocyte cross-sectional area in NP and LP rat groups. The data are reported as the means \pm SED. 
NP

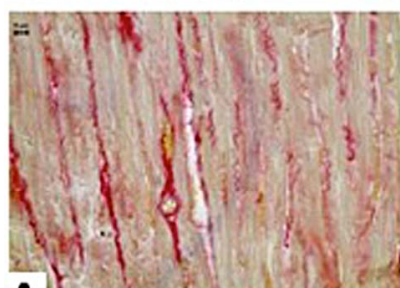

A
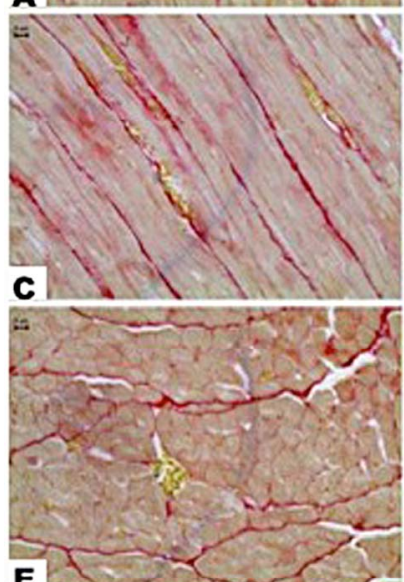

E
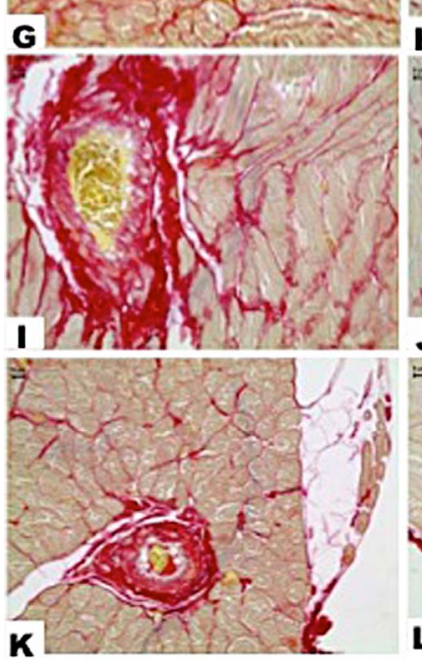

LP

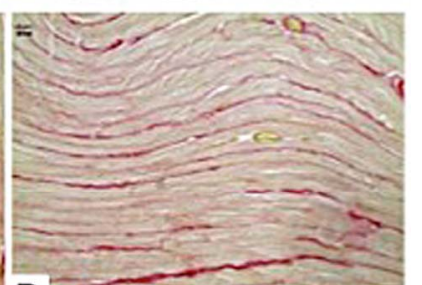

B

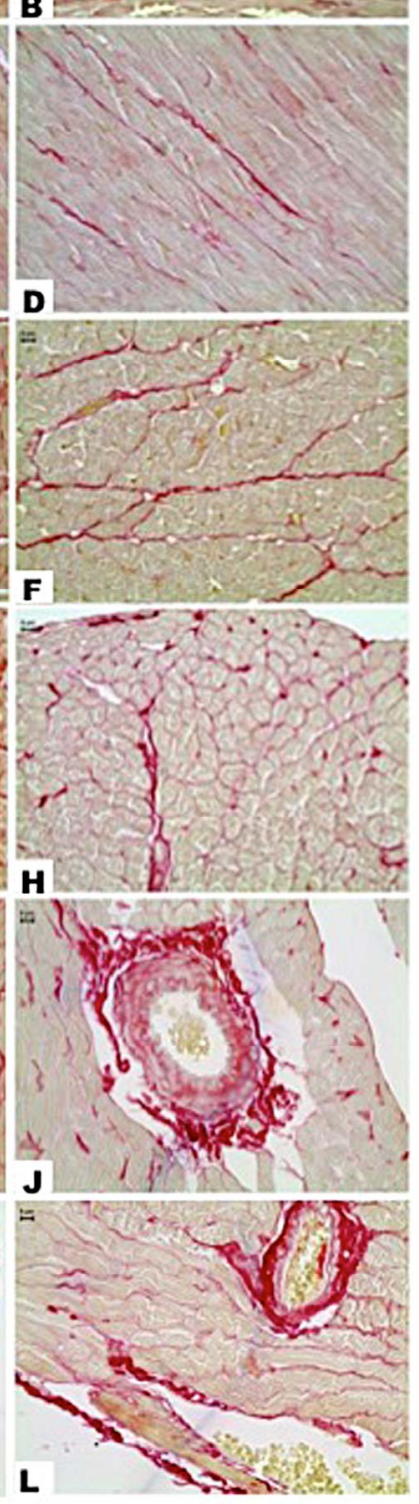

Figure 3. Cardiac left ventricle after Sirius Red. Collagen fibril was stained in red and in NP we can see the normal distribution of collagen in longitudinal (A and $\mathrm{C}$ ) and transversal sections (E and $\mathrm{G})$. In LP is patent the reduction of these fibrils (B, D, F and $\mathrm{H}$ ). By cross-sections of intramural coronary we can see perivascular fibers in a normal pattern (NP, I and K). The LP group presented diminution in perivascular colagenic content $(\mathrm{J}$ and $\mathrm{L}$ ).

4). Analysis by immunoblotting, confirmed by immunohistochemistry, demonstrated a significantly augmented
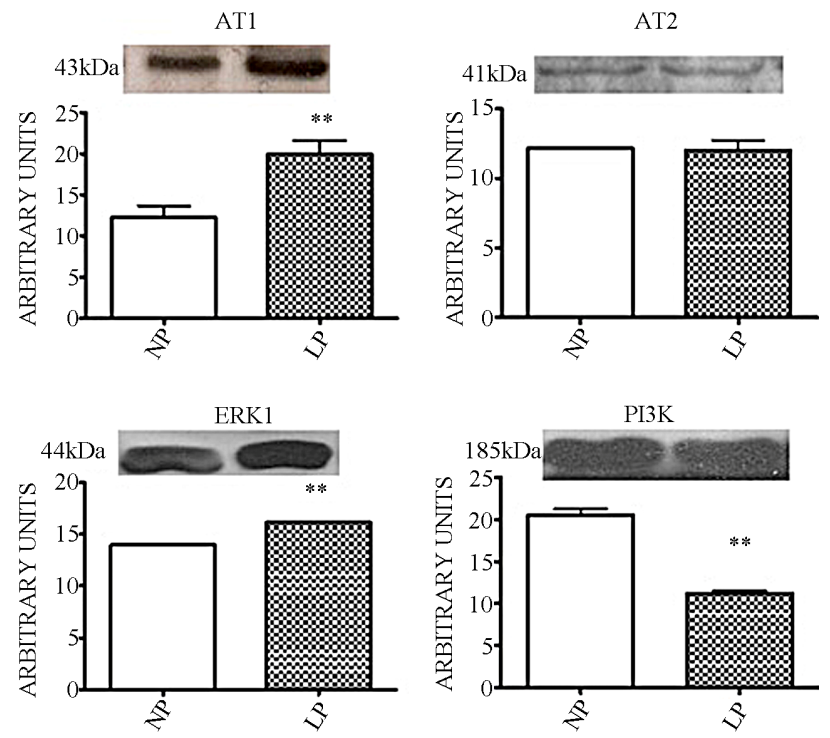

STAT3

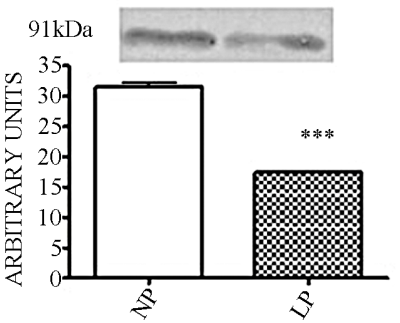

Figure 4. Proteins expression pattern in cardiac left ventricle. Western blot bands densitometry quantification graphics. Columns and bars indicate means $\pm \mathrm{SEM},{ }^{*} \mathrm{P}<0.05$, LP vs. NP.

cardiomyocyte expression of AT1R in LP offspring (NP: $12.27 \pm 1.38$ vs. LP: $19.98 \pm 1.66, \mathrm{P}=0.01$, Figures 4 and 5) and ERK1 (NP: $14.03 \pm 0.064$ vs. LP: $16.23 \pm$ $0.063, \mathrm{P}=0.001$, Figures 4 and 5). On the other hand, the expression of PI3K in LP was significantly reduced in cardiomyocytes and in the intramural coronary wall (NP: $20.52 \pm 0.79$ vs. LP: $11.21 \pm 0.34, \mathrm{P}=0.008$, Figures 4 and 5). By immunohistochemical analysis we verified that LP expression of JAK2 and STAT3 are reduced in both cardiomyocytes and the coronary endothelium (Figure 6). The STAT3 reduction was also verified by western blot (NP: $31.56 \pm 0.74$ vs. LP: $17.41 \pm 2.56$, P $=0.021$, Figure 4).

\section{DISCUSSION}

The hypothesis that a fetus may control its own development according to the intrauterine environment suggests that the offspring adjusts its growth and metabolism. The imbalance between food intakes, homeostasis and energy consumption leads to an increased risk of cardiovascular and metabolic diseases [8,9,13,14]. Herein, we report the development of adult hypertension, in as- 


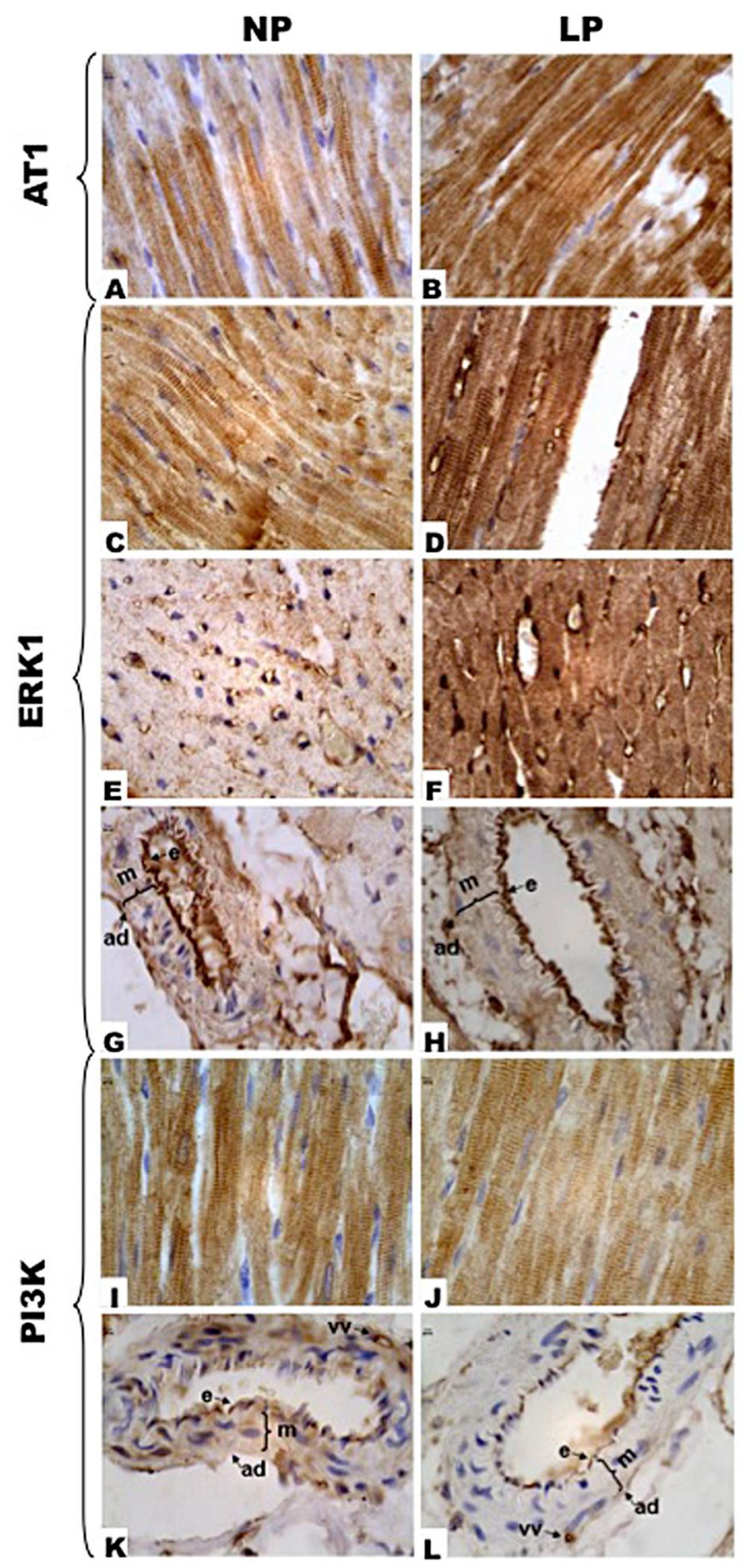

Figure 5. Immunohistochemistry for AT1R, ERK1 and PI3K. LP shows more intensive AT1R expression in cardiomyocytes when compared to NP group. In transversal and longitudinal sections we can observe that blood vessels among cardiomyocytes presented an important ERK1 expression and are better viewed in E. LP group (D and F) has shown enhanced ERK1 expression in cardiomyocytes, and transversal sections turns difficult to visualize blood vessels marks. NP $(\mathrm{G})$ and LP $(\mathrm{H})$ coronaries have not presented ERK1 expression alterations. We observed cytosolic distribution of PI3K in cardiomyocytes and apparent reduction expression in LP. Intramural coronary arteries in NP (K) express PI3K in endothelium (e), tunica media (m) and tunica adventitia (ad) and this expression becomes higher in vasa vasorum (vv). PI3K expression in coronary tunics was drastically reduced in LP animals (L) and becomes restricted to endothelium (e) and vasa vasorum (vv).

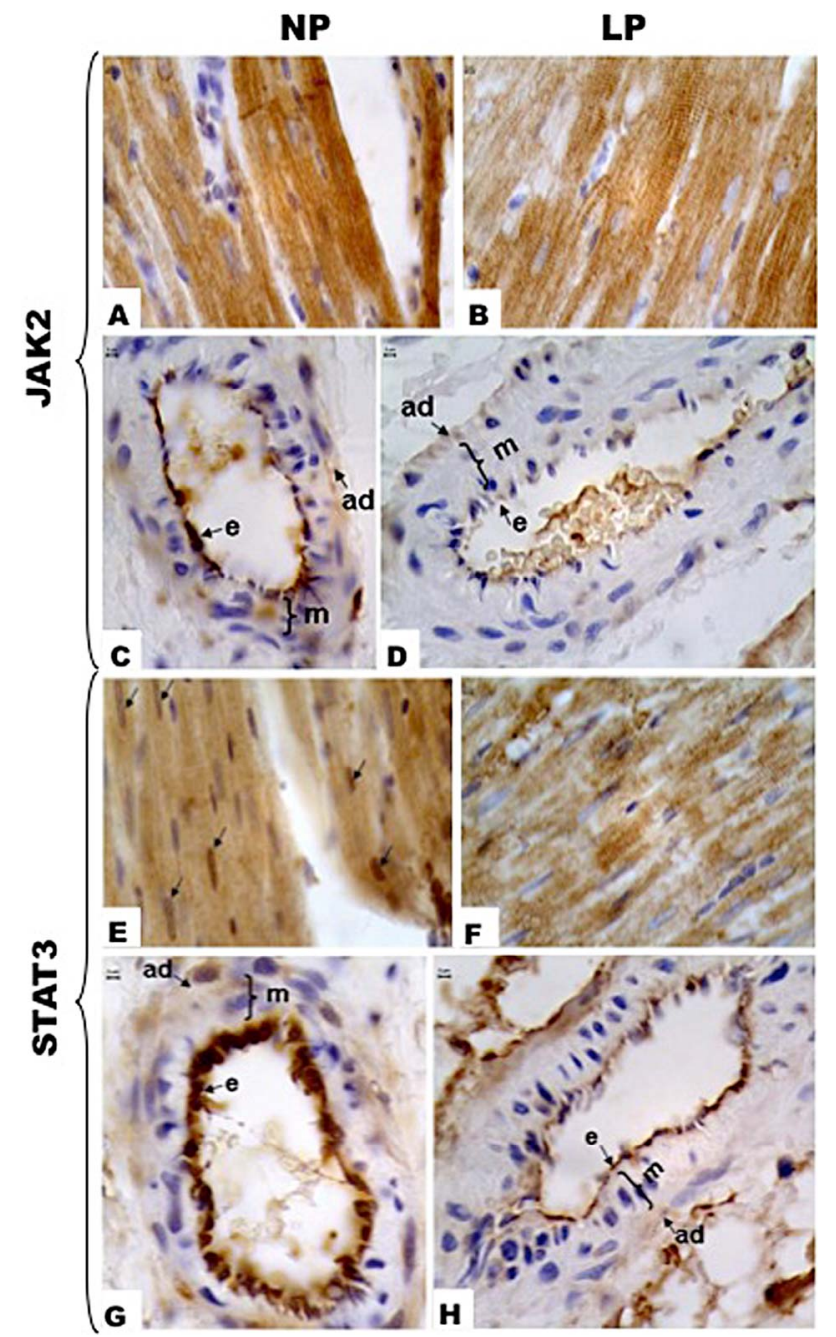

Figure 6. Immunohistochemistry for JAK2 and STAT3. In cardiomyocytes JAK2 has cytosolic distribution and we can observe apparent reduced immunoreactivity in LP (B). In A it is possible to visualize intercalated disks intensively marked. NP group expression of JAK2 occurs in intramurals coronary arteries (C), specifically in endothelium (e). LP animals (D) present a significant reduction of endothelium JAK2 expression. E (NP) and F (LP) show distribution of STAT3 in cardiomyocytes and apparent reduction in LP expression. E indicates strong nuclear localization (arrows) of this protein in NP group, while in LP animals the nuclear expression was reduced. NP group expression of STAT3 occurs in intramurals coronary arteries (G), strongly in endothelium (e). LP animals (H) present a significant reduction of endothelium STAT3 expression. Endothelium (e), tunica media (m) and tunica adventitia (ad).

sociation with left ventricle morphological changes, in a maternal undernutrition offspring model.

The effect of the reduced birth weight was associated with a significant and progressive augmentation in arterial blood pressure in the LP group in parallel with increased left ventricular mass and volume. However, the main mechanisms link an intrauterine adverse environment with the development of hypertensionremain un- 
known. Animal models of fetal programming induced by gestational protein undernutrition or placental insufficiency report common temporal alterations in the RAS $[8,9,15]$. Most of the known physiological effects of AngII are mediated by AT1R, which serve as a control point for regulating the ultimate effects of AngII on its target tissue. In the present study, expression of AT1R was upregulated despite unchanged AT2R expression in the left ventricular maternal 16-wk-old LP offspring, suggesting that the RAS could play a role in fetal heart enlargement following maternal underfeeding. In adult hearts, AngII appears to cause fibrosis and hypertrophy [15]; whereas infusion of AngII in fetal sheep stimulates left ventricular growth [16], in cultures of ovine fetal cardiomyocytes, AngII stimulates hyperplasic growth [17]. Our data in LP 16-wk-old rats may suggest that myocardial hypertrophy is associated with the AngII pathway and is mediated by upregulated AT1R. In the present study, the increased AT1R/AT2R ratio differs from that of Lumbers et al., 2005 [18], who found no significant change in the expression of either of the receptors. On the other hand, disruption of AT2R does not result in histological changes in the heart [19] and more studies are needed regarding the balance between actions mediated by AT1 and AT2 receptors on the myocyte.

The present data confirms previous studies [20] demonstrating that AngII may down regulate the PI3K pathway in the hypertrophied heart model. Alvin and col., 2011 showed that PI3-kinase inhibition negated the AngII-dependent increase in L-type calcium channel current density during the development of volume overload-induced cardiac hypertrophy. Thus, in current animal models of fetal programming, a fall in PI3-kinase expression may represent acounter-regulated target of opportunity for the modulation of hypertrophied hearts to prevent its progression into overt heart failure [21]. In the heart, AngII has been shown to activate signaling cascades that activate MAPKs (Mitogen-activated protein kinase), including ERK1/2, which are implicated in myocyte differentiation, proliferation, and fibrosis [22]. Considering the fact that heart growth involves increases in cardiomyocytes and interstitial fibrosis, we investigated the collagen distribution in the extracellular matrix (ECM). Surprisingly, our results demonstrate a lower heart interstitial collagen deposition in adult LP offspring rats, when compared with the NP age-matched group. However, as previously reported by Ishida et al., 1998 [23], AngII-induced enhanced activation of vascular ERK $1 / 2$ has been implicated in hypertension and in perivascular target-organ damage, as observed in the current study. In the present study, the unchanged left ventricle AT2R expression was accompanied by greater ERK1/2 expression in LP offspring, compared with NP rats.

In the current study, the increased expression of AT1R, associated with the activation of the JAK/STAT mitogenic pathway, was not confirmed as we showed a reduction of JAK2 and STAT3 expression. Accumulating evidence supports PI3-kinase's role in the tyrosine phosphorylation of STATs [24] by cytokine receptors to PI-3 kinase, through JAK [25]. Members of the MAPK family, including ERK, elicited both positive and negative effects on JAK-STAT signaling [26,27]. Both PI3K and MAPK appear to play a central role in the regulation of JAK2/STAT activities; we herein demonstrate that enhanced heart ERK and decreased PI3K both negatively regulate the expression of JAK/STATs and establish new links between these signaling cascades in the regulation of STATs and left ventricle growth.

In conclusion, the current study confirms experimental and epidemiological studies indicating that maternal underfeeding is associated with low birth weight offspring and may result in an increased risk of cardiovascular morbidity in adulthood. Our data also suggest that changes in the RAS may play a role in the ventricular growth through upregulation of the AT1-mediated ERK1/2 response, despite unchanged AT2R expression. In addition, the findings of present study show that maternal underfeeding did not change interstitial structures in adult hearts. Although compelling evidence has been reported to implicate RAS signaling pathways in a variety of myocardial responses, additional studies are required to firmly test these statements and establish its importance in programming disease processes in the heart.

\section{ACKNOWLEDGEMENTS}

This work was supported by Fundação de Amparo à Pesquisa do Estado de São Paulo (Proc. 05/54362-4 and 10/52696-0) and Coordenação de Aperfeiçoamento de Pessoal de Nível Superior.

\section{REFERENCES}

[1] Barker, D. (1998) In uteroprogramming of chronic disease. Clinical Science, 95, 115-128. doi:10.1042/CS19980019

[2] Unger, T. (2003) Blood pressure lowering and reninangiotensin system blockade. Journal of Hypertension, Suppl. 2, S3-S7. doi:10.1097/00004872-200307006-00002

[3] Varagic, J. and Frohlich, E.D. (2002) Local cardiac reninangiotensin system: Hypertension and cardiac failure. Journal of Molecular and Cellular Cardiology, 34, 14351442. doi:10.1006/jmcc.2002.2075

[4] Berecek, K.H., Reaves, P. and Raizada, M. (2005) Effects of early perturbation of the renin-angiotensin system on cardiovascular remodeling in spontaneously hypertensive rats. Vascular Pharmacology, 42, 93-98. doi:10.1016/j.vph.2005.01.010

[5] Holemans, K., Aerts, L. and Van Assche, F.A. (2003) Fetal growth restriction and consequences for the off- 
spring in animal models. Journal of the Society for Gynecologic Investigation, 10, 392-399.

doi:10.1016/S1071-5576(03)00134-5

[6] Ozaki, T., Nishina, H., Hanson, M.A. and Poston, L. (2001) Dietary restriction in pregnant rats causes gender-related hypertension and vascular dysfunction in offspring. Journal of Physiology, 530, 141-152. doi:10.1111/j.1469-7793.2001.0141m.x

[7] Rasch, R., Skriver, E. and Woods, L.L. (2004) The role of the RAS in programming of adult hypertension. Acta Physiologica Scandinavica, 181, 537-542. doi:10.1111/j.1365-201X.2004.01328.x

[8] Mesquita, F.F., Gontijo, J.A.R. and Boer, P.A. (2010) Expression of rennin-angiotensin system signalling compounds in maternal protein-restricted rats: Effect on renal sodium excretion and blood pressure. Nephrology Dialysis Transplantation, 25, 380-388. doi:10.1093/ndt/gfp505

[9] Mesquita, F.F., Gontijo, J.A.R. and Boer, P.A. (2010) Maternal undernutrition and the offspring kidney: From fetal to adult life. Brazilian Journal of Medical and Biological Research, 43, 1010-1018. doi:10.1590/S0100-879X2010007500113

[10] Michelotto, J.B., Carvalheira, J.B., Saad, M.J. and Gontijo, J.A. (2002) Effects of intracerebroventricular insulin microinjection on renal sodium handling in kidney-denervated rats. Brain Research Bulletin, 57, 613-618. doi:10.1016/S0361-9230(01)00754-7

[11] Menegon, L., Zaparolli, A., Boer, P.A., de Almeida, A.R. and Gontijo, JA. (2008) Long-term effects of intracerebroventricular insulin microinjection on renal sodium handling and arterial blood pressure in rats. Brain Research Bulletin, 76, 344-348. doi:10.1016/j.brainresbull.2008.02.027

[12] Romero-Calvo, I., Ocón, B. and Martínez-Moya, P. (2010) Reversible Ponceau staining as a loading control alternative to actin in Western blots. Analytical Biochemistry, 401, 318-320. doi:10.1016/j.ab.2010.02.036

[13] Langley-Evans, S.C. (2001) Fetal programming of cardiovascular function through exposure to maternal undernutrition. Proceedings of the Nutrition Society, 60, 505-513. doi:10.1079/PNS2001111

[14] Breier, B.H., Vickers, M.H., Ikenasio, B.A., Chan, K.Y. and Wong, W.P. (2001) Fetal programming of appetite and obesity. Molecular and Cellular Endocrinology, 185, 73-79. doi:10.1016/S0303-7207(01)00634-7

[15] Zhu, Y.C., Zhu, Y.Z., Lu, N., Wang, M.J., Wang, Y.X. and Yao, T. (2003) Role of angiotensin AT1 and AT2 receptors in cardiac hypertrophy and cardiac remodelling. Clinical and Experimental Pharmacology and Physiology, 30, 911-918. doi:10.1111/j.1440-1681.2003.03942.x

[16] Segar, J.L., Dalshaug, G.B., Bedell, K.A., Smith, O.M. and Scholz, T.D. (2001) Angiotensin II in cardiac pressure-overload hypertrophy in fetal sheep. American Journal of Physiology-Regulatory, Integrative and Comparative Physiology, 281, R2037-R2047.

[17] Sundgren, N.C., Giraud, G.D., Stork, P.J., Maylie, J.G. and Thornburg, K.L. (2003) Angiotensin II stimulates hyperplasia but not hypertrophy in immature ovine cardiomyocytes. Journal of Physiology, 548, 881-891. doi:10.1113/jphysiol.2003.038778

[18] Lumbers, E.R., Boyce, A.C., Joulianos, G., Kumarasamy, V., Barner, E., Segar, J.L. and Burrell, J.H. (2005) Effects of cortisol on cardiac myocytes and on expression of cardiac genes in fetal sheep. American Journal of Physiology -Regulatory, Integrative and Comparative Physiology, 288, R567-R574. doi:10.1152/ajpregu.00556.2004

[19] Dostal, D.E. (2000) The cardiac renin-angiotensin system: Novel signaling mechanisms related to cardiac growth and function. Regulatory Peptides, 91, 1-11. doi:10.1016/S0167-0115(99)00123-8

[20] Alvin, Z.V., Laurence, G.G., Coleman, B.R., Zhao, A., Hajj-Moussa, M. and Haddad, G.E. (2011) Regulation of the instantaneous inward rectifier and the delayed outward rectifier potassium channels by Captopril and Angiotensin II via the Phosphoinositide-3 kinase pathway in volume-overload-induced hypertrophied cardiac myocytes. Medical Science Monitor, 17, 165-172. doi:10.12659/MSM.881843

[21] Schaper, J., Froede, R., Hein, S., Buck, A., Hashizume, H., Speiser, B., Friedl, A. and Bleese, N. (1991) Impairment of the myocardial ultrastructure and changes of the cytoskeleton in dilated cardiomyopathy. Circulation, 82, 504-514. doi:10.1161/01.CIR.83.2.504

[22] Sugden, P.H. and Clerk, A. (1997) Regulation of the ERK subgroup of MAP kinase cascades through G proteincoupled receptors. Cell Signal, 9, 337-351. doi:10.1016/S0898-6568(96)00191-X

[23] Ishida, M., Ishida, T., Thomas, S.M. and Berk, B.C. (1998) Activation of extracellular signal-regulated kinases (ERK1/2) by angiotensin II is dependent on c-Src in vascular smooth muscle cells. Circulation Research, 82, 7-12. doi:10.1161/01.RES.82.1.7

[24] Sharfe, N., Dani, H.K. and Roifman, C.M. (1995) JAK3 protein tyrosine kinase mediates interleukin-7-induced activation of phosphatidylinositol-3' kinase. Blood, 86, 2077-2085.

[25] Takahasi-Tezuka, M., Hibi, M., Fujitani, Y., Fukada, T., Yamaguchi, T. and Hirano, T. (1997) Tec tyrosine kinase links the cytokine receptors to PI-3 kinase probably through JAK. Oncogene, 14, 2273-2282. doi:10.1038/sj.onc.1201071

[26] David, M., Petricoin III, E., Benjamin, C., Pine, R., Weber, M.J. and Larner, A.C. (1995) Requirement for MAP kinase (ERK2) activity in interferon alpha- and interferon beta-stimulated gene expression through STAT proteins. Science, 269, 1721-1723. doi:10.1126/science.7569900

[27] Boccaccio, C., Andò, M., Tamagnone, L., Bardelli, A., Michieli, P., Battistini, C. and Comoglio P.M. (1998) Induction of epithelial tubules by growth factor HGF depends on the STAT pathway. Nature, 391, 285-288. doi: $10.1038 / 34657$ 